\title{
How does EFSUMB spend the 8 euro member's fee?
}

In 2013 EFSUMB received the fee of 8 euro for each of the 19,223 members from the 27 National Societies. The payment for 2014 will be due soon and Societies may be facing similar challenges - falling membership numbers and increasing costs. EFSUMB too has had to face these and for this reason we have been critically reviewing all expenditure. We have outlined the main areas with proposals on how to reduce this still further but we can only do this with your cooperation.

\section{Secretariat}

EFSUMB made the decision a few years ago to find the most effective ways of reducing administration costs. These costs are currently at an all time low. We are of the opinion that the service provided to our members has not been compromised in the process. We have maintained EFSUMB's presence at international events, ECR, UEG Week, EASL and some of the NS annual meetings promoting the 8 Euroson Schools and 11 Endorsed Courses held in 2013, the EFSUMB Course Book on Ultrasound (ECB), the almost completed online ECB Student Edition and the latest EFSUMB Guidelines and Recommendations. All of this is at no further cost to our members.

\section{WFUMB dues}

EFSUMB pays $\$ 1.50$ for each of the 19,223 EFSUMB members to the World Federation of Ultrasound in Medicine and Biology

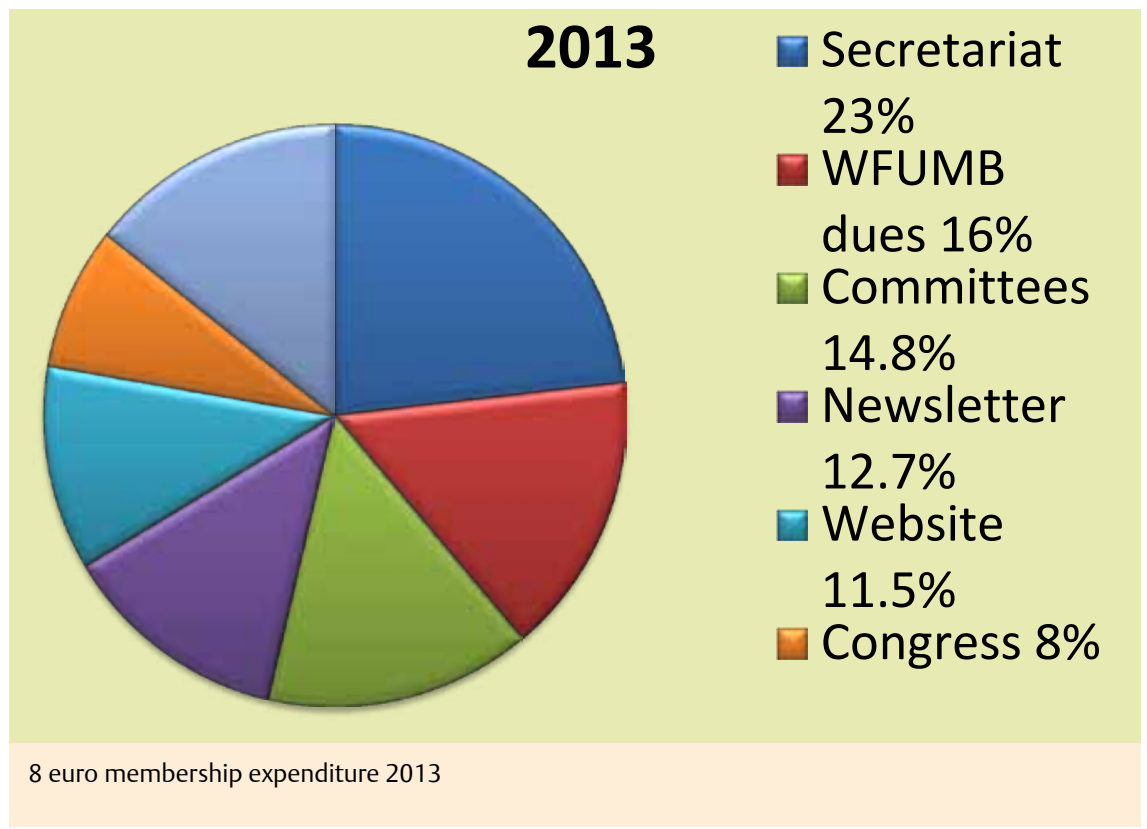

(WFUMB). EFSUMB is the largest Federation within WFUMB and benefits from being a powerful voice on the world stage with representation at all levels within the WFUMB hierarchy.

\section{Committee Meetings}

All Committee meetings are now mainly electronic meetings which enable more frequent and shorter meetings. This is easier to fit into busy schedules with only occasional meetings at Congresses or hosted in the country of a Committee member. These meetings are now centrally organised and planned well in advance to take advantage of the best fares and offers.

\section{EFSUMB EJU Newsletter} $\nabla$

The EFSUMB Newsletter in the EJU is a significant part of the EFSUMB budget which has been reduced by limiting the number of published pages to those covered by our contract with Thieme. It is a hindrance to us that Issue 1 does not reach all our members an issue that is free to all EFSUMB members. Despite requests to National Societies we do not receive mailing addresses for all our members and only 5,700 receive this Issue in addition to the bulk subscribers. Faced with mounting mailing costs the alternative of using email technology for a newsletter distribution seems obvious. If all our members' email addresses were available, we would 
be in a position to negotiate online access and perhaps ensure that all our members receive the Newsletter restricted to six mailings per annum.

\section{Website}

$\nabla$

The area that has seen the biggest increase in expenditure is the EFSUMB website and this has been a success story in terms of numbers of visitors to the site - a quarter of a million hits in the last 3 month survey period. It is pleasing for us to know that those visitors stay and access almost half a million articles. The Case of the Month is the most viewed item which now includes translations into 14 different languages. Our viewers come from all over the world with the latest top ten from UK, USA, Germany, Italy, Spain, Romania,
Sweden, Netherlands, China and Poland. EFSUMB members have commented that as access is open on the website and used by non members alike that this is being subsidised by their fees. The website is seen as fundamental to our educational programme and charitable status and our imminent overhaul of the educational portal, made possible with sponsorship from BRACCO, will feature more interactive learning with EFSUMB CME credits for participation. However if we had the email addresses of all our members we would be in a position to offer a members' corner with exclusive offers and free access to all EFSUMB members. In this way we could reduce our dependency on the EFSUMB membership fee for funding the website.

\section{Congress \\ $\nabla$}

EFSUMB continues to promote the Young Investigator, Safety, Educational and Publication Sessions at EUROSON Congresses. The YI session is one of the most exciting with extremely high standards of presentations. This gives young researchers the opportunity to win the 1000 euro prize, to enjoy the prestige that is associated with winning and also to see the publication of their abstract in the EJU EFSUMB Newsletter.

Why not have your say on any of the above by visiting our forum on the EFSUMB website and telling us what you would like change, improve or just comment on any of these topics: www.efsumb.org 